Калиниченко Максим Петрович канд. экон. наук, ГОУ ВПО «Донецкий национальный университет», г. Донецк

ORCID: 0000-0002-2028-6451

e-mail:mpk79@mail.ru

\section{Kalinichenko Maksim}

Candidate of Economic Sciences, Donetsk National University, Donetsk ORCID: 0000-0002-2028-6451 e-mail:mpk79@mail.ru

\section{ПРЕДПРИЯТИЕ КАК ОБЬЕКТ УПРАВЛЕНИЯ: АКТУАЛЬНЫЕ ПРОБЛЕМЫ, ЭВОЛЮЦИЯ ГАРМОНИЧНОГО ПОДХОДА, ГАРМОНИЯ ИНТЕРЕСОВ}

\begin{abstract}
Аннотация. На основе исторического метода и детерминированности между эволюиией парадигм экономической теории и эволючией теории фирмы сформировано синтетическое понимание сущности предприятия как объекта управления. Обосновано, что в основе предмета теории фирмы должны находиться экономические интересы. Природу, границы и факторы развития фирмы необходимо анализировать и объяснять исходя из проявления и взаимодействия интересов и, как следствие, возникающих экономических отношений. Представлена эволючия гармоничного подхода к управлению, суть которого состоит в формировании целостной системь управления предприятием, скрепляемой общими интересами, общечеловеческими иенностями, интеграцией стратегий, функиий и процессов.
\end{abstract}

Ключевые слова: гармония интересов, гармоничный подход, предприятие, фирма, объект управления, экономические системы, инструменты менеджмент, бизнес.

Цитирование: Калиниченко М.П. Предприятие как объект управления: актуальные проблемы, эволюция гармоничного подхода, гармония интересов//Вестник университета. 2020. № 2. С. 19-25.

\section{ENTERPRISE AS AN OBJECT OF MANAGEMENT: CURRENT PROBLEMS, EVOLUTION OF A HARMONIOUS APPROACH, HARMONY OF INTERESTS}

\begin{abstract}
A synthetic understanding of the essence of the enterprise as an object of management has been formed based on the historical method and determinism between the evolution of the paradigms of economic theory and the evolution of the theory of the company. It has been proved that the subject of the theory of the company should be based on economic interests. The nature, boundaries and development factors of the company should be analysed and explained on the basis of the manifestation and interaction of interests and, as a consequence, emerging economic relations. The evolution of a harmonious approach to management the essence of which is the formation of an integrated enterprise management system, consolidated by common interests, universal values, integration of strategies, functions and processes, - has been presented.

Keywords: harmony of interests, harmonious approach, enterprise, company, management object, economic systems, management tools, business.

For citation: Kalynychenko М.П. (2020) Enterprise as an object of management: current problems, evolution of a harmonious approach, harmony of interests. Vestnik universiteta. I. 2, pp. 19-25. DOI 10.26425/18164277-2020-2-19-25
\end{abstract}

Разработанные экономической и управленческой наукой теории фирмы можно разграничить на фундаментальные и функциональные (далее понятия «фирма» и «предприятие» будем использовать как синонимы). Продолжаются попытки разработать синтетическую теорию фирмы, усовершенствовать инструменты и методы менеджмента на основе понимания закономерностей эволюции предприятия как системы, в которой проходят процессы метаболизма; как института, поддерживающего определенный статус в экономической системе, формирующего механизмы саморегулирования и взаимоотношений с группами заинтересованных сторон (далее - ГЗС); как организации, выступающей игроком на товарном и ресурсных рынках [5; 7].

(C) Калиниченко М.П., 2020. Статья доступна по лицензии Creative Commons «Attribution» («Атрибуция») 4.0. всемирная (http://creativecommons.org/licenses/by/4.0/).

The Author(s), 2020. This is an open access article under the CC BY 4.0 license (http://creativecommons.org/licenses/by/4.0/).

(c) (i) 
Ни одна из теорий фирмы до настоящего времени не приблизилась к наиболее полному соответствию между эмпирической реальностью и теоретическими конструктами.

Цель статьи - сквозь призму развития парадигм экономической науки и теорий фирмы провести исследование эволюции и сущностного содержания гармоничного подхода к согласованию совместных интересов между предприятием как объектом управления и его ключевыми ГЗС.

Современный этап развития экономической науки характеризуется симбиозом и противоборством трех парадигм: неоклассической, институциональной, эволюционной. Существуют различные подходы к классификации парадигм экономической теории (далее - ПЭТ). Непосредственно связанный с нашим пониманием этой проблемы подход представлен в работе Т. В. Петренко, где с позиции исторического метода отражается формирование классической, неоклассической, институциональной, системной и синергетической ПЭТ [10].

Изучение работ представителей классической ПЭТ (начало XVIII в. - 1870-е гг.) показывает, что ими учение о фирме не разрабатывалось, хотя капиталистические мануфактуры рассматривались как производственные единицы. Частный интерес «экономического человека» основан на материальной выгоде («ничего не дается даром, но и сам ничего не делает даром») [12]. Если спроецировать концепцию «экономического человека» на фирму, то в ее крайних проявлениях, т. е. при нарушении гармонии, можно подойти к границам «экономики физических лиц» (по Г. Клейнеру). В такой экономике обнажается ряд проблем, в том числе асимметрия информации; агенты вырабатывают способность демонстрировать оппортунистическое поведение и преследуют только свои корыстные интересы. В современных условиях жизненный цикл такой фирмы будет крайне коротким. Таким образом, «причины богатства», создаваемого в сфере материального производства, во многом не утратили своей актуальности, но современных условиях для ряда руководителей предприятий либерального толка вполне удовлетворительными кажутся многие положения классической ПЭТ.

Экономист либерального направления Ф. Бастиа не входит в main stream классической ПЭТ, который в 1848 г. опубликовал труд «Экономические гармонии». В нем он рассуждает о соотношении частного и общего интересов, о социальном механизме и порядке («гармония не исключает зла, но все более суживает область, отведенную ему»), о том, что для поддержания законных интересов гармоничными «решение надо искать в свободе», а если враждебны друг другу - в принуждении («в первом случае не надо только мешать, во втором надо мешать непременно») [3].

К. Маркс провел глубокий анализ капиталистической промышленности - от первоначальных форм мануфактуры до развитого промышленного капитализма (1867 г.). Он исследовал происхождение мануфактуры из ремесла, основные формы мануфактуры и разделение труда в ней, разъяснил разницу между мануфактурой капиталистической и некапиталистической [9]. Следует обратить внимание на ряд «узких мест» подхода марксистов: научно необоснованно культивируется позиция, что источником стоимости выступает лишь труд наемной рабочей силы, игнорируя при этом интересы труда самого предпринимателя; по сути не рассматриваются интересы клиентов на товарном рынке. Таким образом, вклад К. Маркса в зарождающуюся теорию фирмы и концепцию гармоничного подхода к управлению предприятиями состоит в том, что он раскрыл:

1) категории, представляющие основу теорию фирмы;

2) характеристики форм капиталистических предприятий;

3) внутрифирменные социально-экономические противоречия интересов собственников капитала и собственников рабочей силы;

4) классовую борьбу как способ устранения противоречий интересов.

Марксистами была обоснована необходимость революционного освобождения рабочего класса от всякой эксплуатации, неизбежность социалистической революции для уничтожения капитализма и социалистического переустройства общества. Идеи социалистического строительства в ХХ в. были воплощены в целом ряде государств, что, отразилось на непрерывном поиске оптимальных методов управления предприятиями. Для гармонизации личных, групповых интересов и интересов предприятий в СССР вводились метод хозрасчета (активно в период нэпа, хозяйственной реформы 1965 г., после 1985 г.) и метод внутрихозяйственного обособления. Сущность хозрасчета сводилась не только к развитию самоокупаемости предприятий, повышению ответственности и эффективности использования ресурсов, а также к нивелированию «противоположности интересов между рабочей массой и директорами» у В. Ленина и «интеграции всех видов интересов» у Л. Абалкина $[1 ; 8]$. 
Таким образом, эффективность применения метода хозрасчета на том или ином этапе развития экономики СССР во многом предопределялась степенью его интеграции с системой и методами управления, предъявляя к ним требования: создание условий для самоокупаемости и самофинансирования; необходимость учета экономической обособленности предприятий и наличия у них собственных интересов; интегрированный баланс экономических интересов в сочетании с экономической ответственностью. Суть хозяйствования при хозрасчете - управление интересами с обеспечением сочетания высших интересов с низшими при сохранении ведущей роли первых. На постсоветское пространство для предприятий с децентрализованными системами управления на смену хозрасчету и внутрихозяйственному обособлению как методам согласования интересов пришел «рыночный аналог»: центры ответственности.

Нельзя не обратить внимание на достижения К. Адамецки, который до 1918 г. работал в Донбассе. Его вклад в концепцию гармоничного подхода заключается в следующем: НОТ проводил на основе законов разделения труда и гармонии; выделил виды гармонии (гармония в «устройстве организма» (предприятия); гармония в действии; «духовная гармония»); установил, что нарушение гармонии приводит к возрастанию совокупных затрат [2].

С 1910 г. по 1920 г. выходит работа А. Богданова «Тектология», отправная точка которой - подход к изучению любого явления через его организацию: «организм, организация имеют свою «цель» и «сообразно» ей устроены». «Все интересы человечества - организационные. Изучать любую систему, в том числе предприятие, следует как отношений всех ее частей, так и отношений ее как целого со средой. Соглашаемся с тем, что «попытки формально определить организованность как гармонию, или соответствие частей между собой и с целым, также не решают вопроса; это просто замена слова «организованность» его синонимами. Надо именно выяснить, в чем заключается это соответствие, или гармония...» [4].

Следует указать на неоценимый вклад А. Богданова в достижение поставленной нами цели исследования: эксклюзивность его взглядов о первичности организационной науки, когда прогресс развития систем предполагает формирование адекватных систем управления. Таким образом, можно сделать вывод: реализация системного и гармоничного подходов - это поиск нового сочетания элементов системы управления для достижения целей предприятия, в след за которым должно следовать «гармоничное соединение всех видов ресурсов - людей, идей, средств и предметов производства» и процессов.

На смену классической пришла неоклассическая ПЭТ (с 1870-х гг. по 1980-е гг.). Изложение содержания неоклассического подхода к фирме можно встретить практически в каждом учебнике по экономической теории: фирме отводится выполнение «технической» задачи - преобразовать экономические ресурсы в полезные блага. Среди основных преимуществ неоклассического подхода к фирме, как правило, указывают: проведение анализа на основе математического аппарата; установление зависимости изменения производства от изменения внешних факторов [18]. При имеющихся преимуществах ряд экономистов обращают внимание на совокупность недостатков этого подхода, один из которых - со стороны фирма выглядит как гармоничная структура, основанная на сотрудничестве и полном взаимопонимании, но на практике возникают и вступают в противоречия интересы ГЗС. Имеет место разграничение функций фирмы (сфера производства) и рынка (обмен).

Чтобы разрабатываемый подход в рамках неоклассической ПЭТ соответствовал статусу теории фирмы, необходимо, как минимум, устранить его недостатки. Однако эта цель не была достигнута при очевидном разрыве между неоклассическим подходом к фирме, прикладными экономическими науками и практикой.

Заслуга Й. Шумпетера в рамках цели нашего исследования - ввел принцип «методологического индивидуализма», позволивший понимать суть экономических процессов через индивидуальное поведение. Отправной точкой теоретического анализа выступает экономический субъект (индивид, фирма), который имеет свои интересы и может руководствоваться: стремлением к максимизации полезности, минимизации издержек или желанием избежать риски; традициями, принципами этики. До настоящего времени в экономической науке доминирующие позиции занимает этот принцип, который характерен для исследователей, придерживающихся антропоцентризма. Методологическому индивидуализму можно противопоставить методологический холизм - приоритет рассмотрения целого, которое больше суммы своих частей. Считаем, что эти два принципа в гипертрофированной форме могут терять свое гносеологическое предназначение, релевантность для анализа институциональных и организационных изменений в управлении предприятием.

В рамках стейкхолдерской теории фирмы (СтТФ) Э. Фримена (80-е гг. ХХ в.) достижение основной цели фирмы зависит от удовлетворения интересов широкого круга ГЗС, а сама фирма, ее внешнее и внутреннее 
окружение - совокупность ГЗС с соответствующими интересами [17]. Будем придерживаться аргументации тех исследователей СтТФ, которые считают, что во взаимоотношениях с ГЗС следует найти взаимовыгодные решения, в максимальной степени отвечающее интересам как самой фирмы, так и ее контрагентов. Заметим, СтТФ еще предстоит пройти путь, связанный с разработкой и доведением научно-методических разработок до прикладного уровня использования.

Следует обратиться к результатам исследования СтТФ: на практике равная ответственность фирмы (субъекта управления) перед множеством различных ГЗС не возможна; множественность «центров власти» у фирмы означает, что цели, стратегии и действия фактических и/или формальных собственников зависят от множества ГЗС, являются результатом согласования их интересов (коалиция игроков); только владение остаточными правами - эффективный механизм стимулирования использования активов внутри фирмы: «... надежно подкрепить ...тезис о множественности претендентов на остаточные права и необходимости учета интересов всех ГЗС ...не удалось» $[13 ; 14]$.

При бихевиористическом подходе фирму анализируют как с позиции реальных процессов, так и в ракурсе процессов познания, коллективных процессов коммуникаций и принятия решений. Бихевиористический подход и результаты исследования сетевых форм взаимодействия, маркетинга отношений, СтТФ имеют ряд общих точек приложения. В работах по маркетингу отношений большое внимание уделяется изучению межличностных взаимоотношений, которые складываются внутри фирм и между ними, а также анализу неформальных связей, которые опираются на двусторонние взаимоотношения и функционируют в тени формальных организаций.

Триада бихевиористического и сетевого подходов к фирме, маркетинга взаимоотношений во многом приближена к реальности, так как признает, что цели предприятия могут зависеть от разных ситуаций и ГЗС, которые управляют ею. Это позволяет проводить анализ поведения предприятий причин возникновения конфликтов интересов внутри и за его границами. По мнению Ф. Баттла, маркетинг взаимоотношений основан на аргументах об устойчивой и долговременной прибыли [15]. М. Кристофер убежден, что маркетинг взаимоотношений имеет двуединую направленность и сосредоточен как на привлечении, так и на удержании клиентов, а Д. Шет - осуществляется переход к «просвещенному эгоизму» [20]. Таким образом, к заслугам бихевиористического подхода и маркетинга взаимоотношений можно отнести множественное понимание целей и интересов фирмы, а также описание отдельных инструментов воздействия на механизм взаимодействия для гармонизации интересов между различными ГЗС и предприятием.

В рамках предпринимательского подхода к фирме она создается как реакция на возможность получить прибыль за счет реализации бизнес-идей предпринимателя при сочетании ресурсов. Интересы фирма и интересы предпринимателя совпадают, но при росте размеров фирмы такое единство размывается. Абсолютное совпадение целей, интересов собственников и менеджмента может иметь место на уровне малой фирмы.

Далее необходимо проанализировать, какие существуют способы для гармонизации совместных интересов предприятия с ГЗС, так как от этого зависит решение ряда сложных задач: реализация самой бизнесидеи, возможность привлекать и сочетать необходимые ресурсы и др. Предприниматель для достижения поставленной цели имеет интерес привлечь недостающие экономические ресурсы, что неизбежно приводит к двусторонней зависимости между контрагентами. С. Сиех указал на три формы организации предпринимателем процесса реализации бизнес-идеи: рынок; властная иерархия; консенсуальная иерархия. Эти три формы могут комбинировать три инструмента координации:

1) право принимать решения - использовать методы управления;

2) каналы коммуникаций для распространения знаний;

3) стимулы для поиска средств [19].

Первая форма - рынок: игра, взаимодействие эгоистичных агентов, действующих исходя из собственных интересов. Вторя форма позволяет фирму рассматривать как иерархическую систему, в т. ч. властную. Наряду с рынком и властной иерархией активно развивается сетевая форма координации. Считаем, что эти формы координации дополняют друг друга, могут сопровождаться этической формой координации и быть основаны на: групповом усилии, общности целей, действий и интересов.

Для институциональной ПЭТ 1937 г. - дата «рождения» теории фирмы [16]. Институциональная природа фирмы проявляется в том, что наличие институтов снижает риски, присущие при обменном процессе, т. е. делает ее методологию универсальной при обмене ценностями и гармонизации интересов. ГЗС как субъекты 
соответствующих рынков больше доверяют фирме как институту. Формальные и неформальные институты гарантируют удовлетворение интересов ГЗС.

Таким образом, институциональная теория фирмы - это поиск и объяснение институциональных механизмов для соединения различных ресурсов и согласования интересов их собственников (ГЗС). Различные институциональные теории отражают характеристики и интересы взаимодействия фирмы и ГЗС, которые стремятся их реализовать и гармонизировать, а также затрагивают отдельные стороны предмета теории фирмы - асимметрию информации, пучки прав, пучки контрактов и т. д.

Основной объект управления для неоклассической, бихевиористической и предпринимательской теорий фирмы - ресурсы (входные). По мнению В. Тамбовцева, понимание природы фирмы как пучка ресурсов «несопоставимо ближе к практике управления, чем фирма как совокупность контрактов» [13]. В 1984 г. Р. Рамельтом было введено в оборот понятие «стратегическая теория фирмы» (СТФ) [11]. Результаты исследований состояния СТФ позволили в рамках ее предмета представить фирму «в виде группы индивидов, преследующих различные цели и распоряжающихся разными взаимодополняющими ресурсами, взаимодействующих по приказу менеджеров для решения формулируемых ими задач в рамках как сложившихся процедур (рутин, формальных регламентов и т. п.), так и посредством специально сформированных «разовых» форм взаимодействия». Создание ценностей - это процесс, конституирующий фирму, включает минимальный набор типов ресурсов [13].

В рамках системной ПЭТ Г. Клейнером предложены системно-интеграционная теория предприятия (СИТП) и ресурсно-компетентностная теория фирмы (R\&C-теория) [6; 7]. Для СИТП в отличие от традиционного «несистемного» подхода указывается, что ГЗС, участников связанных с ними сетевых структур, микро- и макросреду следует рассматривать как совокупность пересекающихся, вложенных друг в друга и взаимодействующих подсистем: ментальной, культурной, институциональной, когнитивной, организационно-технологической, имущественной, имитационной, поведенческой [7].

Г. Клейнер при разработке комплексной теории предприятия использовал проецирование знаний из одной сферы на другую в виде аналогии, метафоры, что позволило ему структурировать экономическое пространство предприятия, выделить в нем множество самостоятельных подсистем и их элементов, дополнительные виды ГЗС, а также идентифицировать их интересы. В контексте теории систем существование фирмы он объясняет через «своеобразный системный метаболизм», в основе которого на входе факторы деятельности фирмы, а на выходе - результаты деятельности. Считаем, что такой «системный метаболизм» есть продолжение неоклассического подхода. И хотя неоклассический подход к фирме не давал ответ на внутреннюю организацию процессов, то Г. Клейнер при описании внутренних процессов трансформации факторов в результаты исходит из системной концепции внутреннего устройства фирмы: «за каждый вид факторов отвечает внутрифирменная подсистема управления; между ними существует иерархия» [7].

При построении теории фирмы Г. Клейнер разграничил ресурсы и способности, дал ответ на вопрос о цели фирмы с точки зрения «экзогенного» и «эндогенного» подходов, обозначил взаимодействие теории, стратегии и состояния фирмы. Автор R\&C-теории дал обоснование, что «способности фирмы по эффективному использованию доступных ресурсов зависят от структуры взаимоотношений между фирмой и ГЗС. Для эффективной деятельности необходимо создание на предприятиях такой конфигурации взаимоотношений, чтобы возник баланс прав, ответственности и интересов всех групп» [7].

Соглашаемся с Г. Клейнером, что для устойчивого развития фирмы «необходимо присутствие некоей самостоятельной внутренней центростремительной движущей силы, определяющей меру целеустремленности системы, степень уверенности в ожиданиях, учет интенций других субъектов рынка, уровень притязаний фирмы, а также степень ее саморефлексии». «Душа» фирмы у Г. Клейнера дополняет концепции «мозга фирмы» и «сердца компании» [7]. Подход Г. Клейнера не дает ответы на ряд принципиальных вопросов для теории фирмы, но его выводы имеют высокий потенциал для гармонизации интересов: «душа» фирмы (способности и целевые установки) объективно вынуждена поддерживать гармонию интересов с внутренними и внешними ГЗС, развивая соответствующие способности.

Таким образом, каждый из существующих подходов к фирме формирует целостное понимание предприятия как объекта управления, что необходимо учитывать при разработке системы, структуры и стратегии управления. С позиции исторического метода и жесткой детерминированности между эволюцией ПЭТ и эволюцией теории фирмы следует ряд выводов. На современном этапе развития экономической и управленческой мысли 
неоклассический и институциональный подходы к фирме являются одними из доминирующих. Гармоничный синтез теоретических конструкций фирмы позволяет формировать целостное понимание сущности предприятия как объекта управления, что обогащает теорию и методологию менеджмента. В основе предмета теории фирмы должны находиться интересы взаимодействующих ГЗС, которые стремятся их реализовать, гармонизировать, а не пучки прав, контрактов, ресурсов, способностей и т. п. (все перечисленное - характеристики фирмы или ее ГЗС). Предприятие имеет собственные, имманентные ему, интересы, не сводимые к интересам ГЗС. Природу, границы, внутреннюю организацию и факторы развития фирмы необходимо анализировать и объяснять исходя из проявления и взаимодействия интересов и, как следствие, возникающие экономические отношения, при этом не переключать внимание на отдельные характеристики фирмы как целостный объект управления.

Сочетание принципа методологического индивидуализма и принципа методологического холизма позволит в перспективе переформатировать существующие конструкции теории фирмы и реализовать системный подход для понимания сути экономических процессов на уровне фирмы как объекта управления сквозь призму диалектики совместных интересов. «Душа» фирмы как основа интеграции теории фирмы, ее стратегии и состояния, движущая сила ее устойчивого развития объективно вынуждена стремиться к гармонии с интересами ключевых групп заинтересованных сторон в окружающем пространстве, для поддержания которой ей необходимы соответствующие способности. Гармоничный подход - формирование целостной системы управления предприятием, скрепляемой общими интересами, интеграцией стратегий, функций и процессов.

\section{Библиографический список}

1. Абалкин, Л. И. Полный хозяйственный расчет. Теория, практика, проблемы / Л. И. Абалкин. - М.: Экономика, 1989. - 269 с.

2. Адамецки, К. О науке организации: избр. произв. / К. Адамецки; пер. с польск. - М.: Экономика, 1972. - 191 с.

3. Бастиа, Ф. Экономические гармонии / Ф. Бастиа. - М.: ЭСМО, 2007. -219 с.

4. Богданов, А. А. Тектология - всеобщая организационная наука: в 2-х кн. / А. А. Богданов. - М.: Экономика, 1989. Кн. 1. -304 с.; Кн. 2. -351 с.

5. Капаруліна, І. М. Розвиток підприємства: концепція і технологія дослідження / І. М. Капаруліна. К.: Центр учбової літератури, 2014. $-432 \mathrm{c}$.

6. Клейнер, Г. Б. Теория фирмы - стратегия предприятия - микроэкономическая политика государства / Г. Б. Клейнер // Вестник Российского гуманитарного научного фонда. - 2013. - № 4 (73). - С. 52-69.

7. Клейнер, Г. Б. Системно-интеграционная теория предприятия [Электронный ресурс] / Г. Б. Клейнер // Montenegrin Journal of Economics. - Режим доступа: http://kleiner.ru/wp-content/ uploads/2014/12/ist_integr_2005.pdf (дата обращения: 07.06.2019).

8. Ленин, В. И. Полное собрание сочинений : в 55 томах / В. И. Ленин. - изд. 5-е. - М. : Издательство политической литературы, 1970. - Т. 44. - С. 725.

9. Маркс, К. Сочинения / К. Маркс, Ф. Энгельс. - изд. 2-е. - М.: Госполитиздат, 1955. - Т. 23. - 1960. - 907 с.

10. Петренко, Т. В. Эволюция парадигмы экономической науки в контексте формирования системной парадигмы / Т. В. Петренко // Вестник Таганрогского института управления и экономики. - 2012. - № 1. - С. 23-27.

11. Рамелт, Р. П. К стратегической теории фирмы / Р. П. Рамелт // Вестник С.-Петербургского ун-та. Сер. Менеджмент. 2006. - № 1. - С. 83-102.

12. Смит, А. Теория нравственных чувств / А. Смит. - М. : Республика, 1997. -350 с.

13. Тамбовцев, В. Л. Стратегическая теория фирмы: состояние и возможное развитие / В. Л. Тамбовцев // Российский журнал менеджмента. - 2010. - Т. 8, № 1. - С. 5-40.

14. Agle, B. R., Donaldson, T., Freeman, R. E., Jensen, M. C., Mitchell, R. K., Wood, D. J. Dialogue: Toward superior stakeholder theory // Business Ethics Quarterly. - 2008. - № 18 (2). - Pp. 153-190.

15. Buttle, F. B. Customer Relationship Management / F. B. Buttle. - London: Taylor \& Francis. $-2008 .-522$ p.

16. Coase, R. The Nature of the Firm // Economica. - 1937. - Vol. 4, No. 16.- Pp. 386-405.

17. Freeman, R. E. Stakeholder Management: A Stakeholder Approach / R. E. Freeman. - Marshfield, MA: Pitman Publishing, 1984. $-277 \mathrm{p}$.

18. Hart, O. An Economist's Perspective on the Theory of the Firm // Columbia Law Review. - 1989. - Vol. 89, No. 7. - Pp. 1754-1774.

19. Hsieh, C. C., Nickerson, J. A., Zenger, T. R. Opportunity discovery, problem solving and a theory of the entrepreneurial firm // Journal of Management Studies. - 2007. - No. 44 (7). - Pp. 1255-1277. 
20. Sheth, J. N. Sheth, J. N., Parvatiyar, A. Relationship Marketing in Consumer Markets: Antecedents and Consequences // Journal of the Academy of Marketing Science. - 1995. - Vol. 23, No. 4. - Pp. 255-271.

\section{References}

1. Abalkin L. I. Polnyi khozyaistvennyi raschet. Teoriya, praktika, problemy [Full economic calculation. Theory, practice, problems]. Moscow, Ekonomika, 1989. 269 p.

2. Adamecki K. O nauke organizatsii [About the science of organization]. Moscow, Ekonomika, 1972, 191 p.

3. Bastia F. Ekonomicheskie garmonii [Economic Harmonies], Moscow, ESMO, 2007. 219 p.

4. Bogdanov A. A. Tektologiya - Vseobshchaya organizatsionnaya nauka [Tectology - general organizational science], Moscow, Ekonomika, 1989. Book 1, 304 p., book 2, 351 p.

5. Kaparulina I. M. Rozvitok pidpriemstva: kontseptsiya i tekhnologiya doslidzhennya [Enterprise development: research concept and technology], Kyiv Tsentr uchebnoi literatury, 2014. 432 p.

6. Kleiner G. B. Teoriya firmy - strategiya predpriyatiya - mikroekonomicheskaya politika gosudarstva [Theory of the company strategy of the enterprise - microeconomic policy of the state]. Vestnik Rossiiskogo gumanitarnogo nauchnogo fonda [Bulletin of the Russian Humanitarian Science Foundation], 2013, no. 4 (73), pp. 52-69.

7. Kleiner G. B. Sistemno-integratsionnaya teoriya predpriyatiya [System-integration theory of the enterprise]. Montenegrin Journal of Economics. Available at: http://www.kleiner.ru/wp-content/uploads/2014/12/ist_integr_2005.pdf (accessed 07.11.2019).

8. Lenin V. I. Polnoe sobranie sochinenii: v 55 tomakh [Complete Works: in 55 volumes]. Moscow, Izdatel'stvo politicheskoi literatury, 1970. Vol. 44. 725 p.

9. Marks K., Engel's F. Sochineniya [Works]. Moscow, Gospolitizdat, 1955, Vol. 23, 1960. 907 p.

10. Petrenko T. V. Evolyutsiya paradigmy ekonomicheskoi nauki v kontekste formirovaniya sistemnoi paradigmy [The evolution of the paradigm of economic science in the context of the formation of a systemic paradigm]. Vestnik Taganrogskogo instituta upravleniya i ekonomiki [Bulletin of the Taganrog Institute of Management and Economics], 2012, no. 1, pp. 23-27.

11. Ramelt R. P. K strategicheskoi teorii firmy [To the strategic theory of the company]. Vestnik St.-Peterburgskogo universiteta. Seriya: Menedzhment [Bulletin of St. Petersburg University. Series: Management], 2006, no. 1, pp. 83-102.

12. Smit A. Teoriya nravstvennykh chuvstv [Theory of moral feelings]. Moscow, Respublika, 1997. 350 p.

13. Tambovtsev V. L. Strategicheskaya teoriya firmy: sostoyanie i vozmozhnoe razvitie [The strategic theory of the company: state and possible development]. Rossiiskii zhurnal menedzhmenta [Russian Management Journal], 2010, no. 1 (8), pp. 5-40.

14. Agle B. R., Donaldson T., Freeman R. E., Jensen M. C., Mitchell R. K., Wood D. J. Dialogue: Toward superior stakeholder theory. Business Ethics Quarterly, 2008, no. 18 (2), pp. 153-190.

15. Buttle F. B. Customer relationship management. London, Taylor \& Francis, 2008. 522 p.

16. Coase R. The Nature of the firm. Economica, 1937, vol. 4, no. 16, pp. 386-405.

17. Freeman R. E. Stakeholder management: A Stakeholder Approach. Marshfield, MA, Pitman Publishing, 1984.277 p.

18. Hart O. An Economist's Perspective on the theory of the firm. Columbia Law Review, 1989, vol. 89, no. 7, pp. 1754-1774.

19. Hsieh C., Nickerson J. A., Zenger T. R. Opportunity discovery, problem solving and a theory of the entrepreneurial firm. Journal of Management Studies, 2007, vol. 44 (7), pp. 1255-1277.

20. Sheth J. N., Parvatiyar A. Relationship marketing in consumer markets: Antecedents and consequences. Journal of the Academy of Marketing Science, 1995, vol. 23, no. 4, pp. 255-271. 